\title{
Sindicalismo docente e política educacional: tensões e composições de interesses corporativos e qualidade da educação
}

\section{Teachers' unionism and educational politics: tensions and compositions of corporate interests and quality in education}

\author{
Andréa Barbosa Gouveia ${ }^{1}$ \\ Marcos Alexandre dos Santos Ferraz ${ }^{2}$
}

\begin{abstract}
RESUMO
O Sindicalismo docente brasileiro tem suas raízes em antigos movimentos ao redor da construção de um Sistema Público de Ensino no país. Desde o movimento dos pioneiros, passando pela LDB de 1946, pelos debates ao redor do capítulo de educação na Constituinte de 1988 e a LDB de 1996; as reivindicações de base corporativa dos professores estiveram estruturalmente vinculadas aos conflitos sobre as condições de oferta do ensino público e sua incidência na qualidade da educação. Com o novo quadro institucional, resultante da Constituição de 1988, que legalizou a representação sindical docente e, numa perspectiva participativa, abriu um amplo leque de Conselhos, que se tornaram novos espaços de ação sindical, justifica-se a necessidade de estudos comparativos entre casos locais. Este trabalho, a partir de uma base empírica que se apoia em entrevistas com dirigentes dos sindicatos de trabalhadores em educação das cidades de Curitiba, Fazenda Rio Grande, Araucária e Piraquara, no Paraná, e Dourados, no Mato Grosso do Sul, analisa a ação sindical docente nos últimos 15 anos, explicitando como se articulam interesses corporativotrabalhistas e política educacional, sob a ótica dos Sindicatos.
\end{abstract}

Palavras-chave: política educacional; sindicalismo docente; corporativismo.

${ }^{1}$ Doutora em educação pela Universidade de São Paulo. Professora da Universidade Federal do Paraná, Programa de Pós-Graduação em Educação (PPGE), Brasil. E-mail: andreabg@ufpr.br.

2 Doutor em sociologia pela Universidade de São Paulo. Professor da Universidade Federal da Grande Dourados. Programa de Pós-Graduação em Sociologia, Brasil. E-mail: ferrazmarcos@uol.com.br 


\begin{abstract}
The Brazilian teachers' unionism has its roots in older movements around the Public Education System building. Since the pioneering movement, passing through LDB - the Education Brazilian Law from 1946, and through debates around the Education Chapter in the Federal Constitutional Assembly in 1988 and the Education Law from 1996; the teachers' claims of corporate foundation were structurally linked with fights about public education offering conditions and their incidence on education quality. With the new institutional framework, resulted from the Federal Constitution of 1988, which legalized the teachers' union representation and, in the participative perspective, opened the wide range of councils which became new spaces to syndical action, the need of comparative studies on local cases is justified. In this article, from the empirical data of interviews with education union leaders from Curitiba, Fazenda Rio Grande, Araucaria and Piraquara, that are municipalities in Parana State, and from Dourados, in Mato Grosso do Sul State, the teachers' union action in the last 15 years was analyzed, explaining how the corporate-labor interests are articulated to educational policies, in the view of Unions.
\end{abstract}

Keywords: educational policies; teachers' unionism; corporatism.

Existem muitas entradas para o debate sobre políticas educacionais: a legislação, os indicadores de oferta, a ação política dos diferentes atores. Em especial, quando se propõem discutir a política educacional a partir da ação política, a mirada a partir do movimento sindical se apresenta como uma alternativa interessante, tanto em termos da agenda da luta - o que pode revelar os temas conjunturais -, quanto em termos dos espaços institucionalizados ou não para que esses atores influenciem (ou busquem influenciar) a política.

Este artigo apresenta parte de resultados de duas pesquisas sobre sindicalismo docente ${ }^{3}$ e se propõe a discutir a ação de sindicatos e/ou associações em municípios do Paraná e do Mato Grosso do Sul, mapeando a forma como, no contexto municipal, o movimento sindical estabelece estratégias para discutir as questões corporativas e gerais da educação. Para este debate privilegiam-se como fonte de informação - entrevistas com dirigentes sindicais de municípios, ainda que com informações complementares de fontes documentais.

${ }^{3}$ Ação sindical docente e investimento em educação na Região Metropolitana de Curitiba/ PR (Edital MCT/CNPq/MEC/CAPES N ${ }^{\circ}$ 02/2010) e Ação sindical docente e investimento em educação: análise comparada de municípios nas regiões da Grande Dourados/MS, Campo Grande/ MS e Região Metropolitana de Curitiba/PR ( Edital MCT/CNPq 02/2009). 


\section{Um pouco de história}

Ainda que de forma rápida e esquemática, ao se tentar fazer um resgate histórico sobre as principais conjunturas de transformações na política educacional brasileira, encontramos um cenário de conflito político no qual as organizações docentes não são atores políticos negligenciáveis. É sempre impreciso estabelecer a gênese de um ator social ou de uma política pública. No entanto, não nos parece nada recomendável recuar, para os propósitos do nosso debate, até o período colonial da história brasileira, vista a quase completa omissão, por parte do poder colonial, no que diz respeito à implementação de qualquer política social pública consequente naquela conjuntura. Assim, por omissão ou conivência do Estado, o processo educativo estava completamente entregue a atores privados, em especial à Igreja Católica.

Assim, é com o processo de independência em 1822 e, na sequência, com a Constituição de 1824, que se encontra o primeiro esboço de uma política educacional no Brasil. Essa política educacional, apontada pela Constituição de 1824, já contemplava o princípio da gratuidade. No entanto, a mesma norma legal era explícita ao garantir, apenas aos cidadãos livres, o acesso à educação. Esse dispositivo excluía escravos, indígenas e mulheres. Ou seja, a grande maioria da população brasileira. Mas, como registra Subirá (2012), esta exigência constitucional culminou com a outorga de um Decreto-Lei Imperial, em 1827, que inaugura a descentralização da responsabilidade pela oferta da educação para as províncias e regulamenta, pela primeira vez, um conjunto de condições de remuneração e contratação dos professores públicos.

É possível, portanto, compreender nesse Decreto o reconhecimento legal e político de um coletivo corporativo ${ }^{4}$, visto que no Sistema de Aulas Régias, do período colonial, o professor era sempre uma figura individual e privada. Com esse reconhecimento, principalmente político, começam a se estruturar bases objetivas para as primeiras entidades representativas docentes, que começaram a nascer no final do Segundo Império. Vicentini e Lugli (2009) identificaram, ainda no período imperial, a Sociedade Literária Beneficente Instituto dos Pro-

${ }^{4}$ Dizer que uma norma legal é um marco no reconhecimento político de um coletivo não significa dizer que as mobilizações e lutas populares só existem a partir do reconhecimento na estrutura do Estado. O que se pretende expressar com essa afirmação é que uma norma legal configura um novo universo cognitivo para a ação política, no sentido de consolidar uma legitimidade de atores e discursos. Em outras palavras, a fala dos atores sociais deixa de ser simples ruído, para adentrar o cenário público como representação de um interesse legítimo, e não apenas um casuísmo sem validade pública. Essa maneira de interpretar a relação entre norma legal e ação social é devedora de Arendt (1989), Lefort (1987), Rancière (1996) e Telles (1999). 
fessores Públicos da Corte (1874-1875), a Caixa Beneficente da Corporação Docente do Rio de Janeiro (1875), a Associação dos Professores Públicos da Corte (1877), o Grêmio dos Professores Primários de Pernambuco (1879) e o Grêmio dos Professores Públicos Primários da Corte (1881).

A proclamação da República não implicou em uma mudança legal ampla nesse quadro, ainda que tenha promovido, do ponto de vista político, um novo cenário de atuação para os poucos atores sociais existentes no período. Nesse contexto, a simples perspectiva liberal e universal de seleção para cargos públicos, que Camargo e Jiacomini (2011) identificam nos artigos 72 e 73 da Constituição de 1891, é suficiente para dar novo fôlego organizativo aos professores que, nesse período, criaram associações em mais dois novos estados - São Paulo e Paraná - e fizeram duas tentativas de efetivar uma organização nacional de professores (VICENTINI; LUGLI, 2009).

Se do ponto de vista corporativo ${ }^{5}$ nem sempre as associações de professores tinham vida longa naquele período e pouco chegaram a representar uma força política, o contexto republicano possibilitou a organização de professores, educadores e outros profissionais liberais ao redor da questão educacional. Assim, ao longo dos anos de 1920, diversas reformas estaduais foram praticadas, sob a liderança de educadores que, em 1924, se reuniriam na Associação Brasileira de Educação - ABE (ROMANELLI, 1996). Nos conflitos entre o caráter laico ou confessional do ensino, no interior da $\mathrm{ABE}$, produz-se uma transformação qualitativa na ação política docente que deixa de ser puramente reativa para adentrar, com visão ideológica e com interesses próprios, o cenário de disputa dos rumos da política educacional. Assim, a ABE passa a desempenhar importante papel na realização das Conferências Nacionais de Educação e, já no período getulista, expressa publicamente suas convicções através do Manifesto dos Pioneiros, em 1932. Mas, se a ABE se torna expressão nacional de uma visão política e ideológica da educação, que repercute no conteúdo da própria legislação nacional do período getulista, a oferta de ensino não deixou de ser descentralizada através de sistemas estaduais, o que contribuiu para o

${ }^{5} \mathrm{O}$ debate sobre o corporativismo no sindicalismo é diverso e tem o significado de um arranjo político amplo no qual os interesses de grandes coletivos são contemplados através de pactos que garantam a reprodução tanto do capital quanto de setores específicos do trabalho. Comumente, o sindicalismo corporativo - que busca, em primeiro lugar, os ganhos materiais de categorias específicas - se contrapõe ao sindicalismo de classe - que visaria à superação do modo de produção capitalista, possibilitando autonomia a toda classe trabalhadora. Na ciência política, o termo político corporativismo também pode ser usado como contraponto ao conceito de pluralismo. Sobre essas diferentes abordagens ver: Almeida (1996), Bobbio (2004), Boito Jr (1994) ou Reis (1995). No presente texto, o termo corporativismo é tomado em sentido mais limitado e modesto. Significa, simplesmente, um conjunto de demandas materiais e/ou políticas, de ordem trabalhista, que representam interesses específicos da categoria docente. 
nascimento de entidades de professores primários e secundários nas décadas de 1930 e 1940, nos diversos estados brasileiros.

O período democrático que se segue ao fim do Estado Novo é marcado pela tensão entre centralização e descentralização na educação brasileira e, tanto a Constituição de 1946 quanto a LDB de 1961 tentam conferir uma maior coesão ao conjunto disperso da legislação getulista. A perspectiva é resolver a questão através de uma maior centralização do Sistema de Ensino. No entanto, essa perspectiva terá pouca efetividade prática, pois é rapidamente interrompida pelo golpe de 1964. De qualquer maneira, a preocupação com a organização de um sistema nacional refletia, em parte, a demanda de professores que não apenas tinham reivindicações nacionais, como o piso salarial de Cr\$3 mil para os professores de todo o Brasil, em 1953 (VICENTINI; LUGLI, 2009, p. 139), mas davam passos importantes para consolidar sua representação nacional, com a criação da Confederação dos Professores Primários do Brasil - CPPB, em 1960. Essa entidade, mais tarde, em 1973, passa a ser a Confederação dos Professores do Brasil - CPB, e, em 1990, dá origem à Confederação Nacional dos Trabalhadores em Educação - CNTE.

O regime militar que se segue ao golpe de 1964 não apenas interrompe prematuramente o debate sobre a organização do sistema nacional, como impulsiona um processo ampliado de descentralização que atingirá o nível municipal de oferta de ensino. Nessa perspectiva, a reforma do ensino de $1^{\circ}$ e $2^{\circ}$ graus, configurada na Lei 5692/1971, tem como consequência um crescimento exponencial da oferta de matrículas. Para atender essa nova demanda induzida, vislumbra-se um duplo movimento: de um lado, há um impulso na profissionalização do magistério, representado pela exigência de Estatutos Estaduais e Municipais; mas por outro, a insuficiência de mão de obra capacitada e de fontes regulares de financiamento no interior do Estado produziu a incorporação de um número elevado de leigos no sistema de ensino. Contudo, esse duplo movimento nas condições de trabalho significa, do ponto de vista da organização política de interesses, o horizonte político e simbólico da luta pela valorização profissional, em um contexto objetivo de precariedade das condições de trabalho. Esse cenário, aliado ao contínuo crescimento absoluto do número de professores, configurou um conjunto ideal de condições sociais objetivas para o crescimento da atividade política de cunho corporativo, que resultou nas greves de finais dos anos de 1970 e início de 1980. É nessa conjuntura que as associações de professores começam a assumir um caráter propriamente de representação de interesses, dando origem, após a Constituição de 1988, a entidades propriamente sindicais.

Em síntese, esse breve histórico permite compreender algumas características que se tornaram estruturantes da ação política de professores: 1) a coexistência entre ações corporativas e ações de disputa sobre os rumos da 
política educacional; 2) a coexistência entre associações de caráter trabalhista e entidades associativas sobre a temática educacional, por exemplo, a convivência entre a CPPB e a ABE, ou mais recentemente a CNTE, o Fórum Nacional de Defesa da Escola Pública e a Campanha Nacional pelo Direito à Educação; e 3) a diversidade das entidades de representação, fruto tanto da descentralização do Sistema de Ensino quanto do período e das peculiaridades regionais em que foram fundadas.

\section{O Sindicato se fortalece}

O final dos anos de 1970, a década de 1980 e a primeira metade dos anos de 1990 presenciaram transformações qualitativas na prática de mobilização coletiva e de representação de interesses dos professores brasileiros, assim como a consolidação de um novo marco institucional para a política educacional. No final dos anos de 1970, em função das reformas educacionais do regime militar, o número de professores na rede pública havia crescido exponencialmente, a perspectiva de profissionalização e valorização do magistério havia sido sinalizada pelos Estatutos Estaduais e Municipais do Magistério, mas as condições de trabalho permaneciam precárias e o rendimento dos professores sofria um processo de depreciação constante, principalmente após a crise do petróleo. Esse cenário de arrocho salarial e a perspectiva de construção de uma identidade profissional tornaram-se combustíveis para um ciclo de mobilizações coletivas e de greves, com caráter tipicamente trabalhista que os professores ainda não tinham experimentado em toda a história brasileira (NOGUEIRA, 2005; GEROLMO, 2009; FERREIRA JR., 2003; BIASOTTO; TETILA, 1991; BULHÕES; ABREU, 1992).

A greve de professores não era exatamente uma novidade. Desde a década de 1950, o dia do professor já havia se tornado um momento de disputa pública pela representação simbólica da profissão. Em 1958, o jornal Última Hora registrou no título de uma matéria sobre o dia 15 de outubro: "Festejos e lutas (por salários mais dignos) marcam o dia do professor" (VICENTINI; LUGLI, 2009, p. 177). E, no caso paulista, em 1963, é deflagrada a primeira greve da categoria. A novidade do final dos anos de 1970, portanto, não foi a greve em si, mas a intensidade, o alcance e a sua radicalidade. Elas não apenas atingiram a maioria dos estados brasileiros, como, em muitos casos, paralisaram, inclusive, pequenas cidades do interior dos estados. Também foi fundamental a aproximação entre as lideranças dessas greves do magistério com as demais 
lideranças do sindicalismo operário, algo inédito até então, no caso brasileiro. Não por coincidência, diversos professores que estiveram à frente dessas greves foram encontrados nas negociações para a criação da Central Única dos Trabalhadores e se tornaram lideranças importantes em partidos de esquerda e centro-esquerda, como o PT, o PCdoB, o PMDB, o PSB e o PDT.

Se a coexistência entre associações de caráter trabalhista e entidades associativas sobre a temática educacional já era uma constante do período anterior ao final dos anos de 1970, neste momento das grandes greves e da legitimação de novas lideranças na passagem entre o regime autoritário e o novo cenário democrático que se abriria em seguida, o equilíbrio entre esses dois tipos de organização sofre uma inflexão. As novas lideranças dos professores eram tipicamente trabalhistas e vislumbravam, na atividade sindical massiva, o caminho para o reconhecimento profissional. É nessa conjuntura que se iniciam os debates sobre a Constituição de 1988, após o fim do regime militar.

Esse cenário não significou a substituição da pauta geral da política educacional pela pauta corporativa, nem tampouco a derrota das entidades associativas sobre a temática educacional para as associações de caráter trabalhista. Também não há um predomínio das lideranças trabalhistas. Ao longo dos debates constituintes, a hegemonia do campo progressista, no que tange aos debates educacionais, permanecerá na mão do Fórum Nacional em Defesa da Escola Pública e dos Fóruns Estaduais, ao longo dos debates das Constituições Estaduais. Mas um novo tipo de ator começa a acumular forças dentro do cenário educacional - os dirigentes trabalhistas dos professores e sua ampla base espalhada por todos os entes federados do país.

É esse ator, conjuntamente com as lideranças de outros servidores públicos, o responsável pelo inciso VI, do artigo 37 da Constituição de 1988, que garante ao servidor público civil o direito à livre associação sindical, e pelo inciso VII, do mesmo artigo, que garante o direito de greve ao servidor. Tais mudanças legais impulsionaram a transformação de antigas associações de professores e de outros trabalhadores em educação em sindicatos trabalhistas. Essa transformação garantiu nova base jurídica, assim como maior regularidade de arrecadação, para as ações políticas e coletivas dos professores. Mas o direito dos professores públicos à filiação e representação sindical foi apenas uma das novas bases institucionais da Constituição de 1988 para a valorização profissional dos docentes.

A Constituição de 1988 também inovou em termos de gestão do sistema educacional, em seu inciso VI, do artigo 206. Com esse inciso, pela primeira vez, uma constituição brasileira registra o princípio da gestão democrática como orientador da atividade de ensino público, e fortalece o princípio geral da Constituição que aponta para a democracia participativa. Da mesma maneira, 
a vinculação orçamentária para manutenção e desenvolvimento do ensino, que havia voltado à pauta com a emenda Calmon, de 1984, é consagrada no artigo 212. E no que diz respeito diretamente à vida profissional do professor, o inciso V, do artigo 206, prevê a valorização do magistério através de planos de carreira e ingresso nas Redes de Ensino exclusivamente por concursos públicos de provas e títulos. Por fim, no inciso VIII, do mesmo artigo, a antiga reivindicação de um piso salarial nacional para os profissionais da educação é transformada em princípio constitucional.

É evidente que a aprovação de um princípio constitucional não significa uma imediata execução da política educacional por ele vislumbrada. No entanto, como marco institucional, ele desenha um campo cognitivo preciso para a sequência dos conflitos políticos. Assim, toda a mobilização social ao redor da Lei de Diretrizes e Bases da Educação e todos os embates travados no interior do Congresso Nacional na definição do texto da Lei 9.394/1996 se dão na disputa pelo significado de cada um dos artigos, parágrafos e incisos do capítulo sobre educação da Constituição de 1988. É, portanto, dentro desse campo de significação política que a LDB estabelecerá a definição sobre quais são os gastos com manutenção e desenvolvimento do ensino, aprofundando a vinculação orçamentária. Em relação à preocupação com a qualidade do ensino, a LDB incorporou a educação infantil como primeira etapa da educação básica, estabeleceu um processo nacional de avaliação e distribuiu, de forma mais explícita, as obrigações dos diferentes entes federados. Quanto ao processo de maior profissionalização da atividade docente, a Lei de Diretrizes e Bases estabeleceu a progressão funcional como critério para a construção de Planos de Carreira do Magistério, assim como explicitou a necessidade de formação continuada dos professores.

Da mesma forma, é a continuidade desse quadro de referência política que estabelece os limites do debate ao redor das políticas de fundo que ganharam corpo com a Emenda Constitucional 14/1996 e a Lei do Fundef(Lei 9.424/1996), que tem continuidade na Emenda Constitucional 53/2007 e na Lei do Fundeb (Lei 11.494/2007). Assim, tanto o princípio da gestão democrática ganha mais nitidez com os Conselhos de Acompanhamento e Controle Social do Fundef e do Fundeb, como o direito ao acesso universal de qualidade ganha contornos de enfrentamento das diferentes capacidades de financiamento dos diversos entes federados. Ou seja, é explicitada a necessidade de diminuir as desigualdades regionais no financiamento da educação. Por fim, ao exigir a aplicação de $60 \%$ dos recursos do fundo para pagamento de pessoal do magistério e indicar a construção de Planos de Carreira como estratégia de valorização do magistério, as leis do Fundef/Fundeb colocam essa questão na pauta de enfrentamento de sindicatos docentes e gestores do sistema de ensino. 
Ao longo desses embates, os sindicatos, ainda que nem sempre tenham conseguido as mesmas mobilizações dos anos de 1980, ganharam em sindicalizados (CARDOSO, 2003), em estrutura organizacional, em arrecadação financeira e em legitimidade de representação, tanto aos olhos da base de professores, como dos outros atores sociais. Essa representatividade fica evidente quando se olha a presença dos sindicatos docentes e da CNTE nos diversos conselhos direta ou indiretamente ligados ao funcionamento do sistema de ensino, como os Conselhos Nacional, Estaduais e Municipais de Educação; os Conselhos do Fundef e do Fundeb; os Conselhos de Alimentação Escolar; e os Conselhos Fiscais e de Curadores dos Sistemas de Previdência dos Servidores.

No início dos anos 2000, com a eleição de um presidente com base política no movimento sindical de trabalhadores, os sindicatos de professores, através da representação da CNTE, fortalecem sua posição nos embates pela definição da pauta política nacional. É nessa nova conjuntura que se desenvolvem as disputas ao redor da Lei do Fundeb, em 2007; da Lei do PSPN - Piso Salarial Profissional Nacional -, em 2008; da CONAE - Conferência Nacional de Educação -, em 2010; e do Plano Nacional da Educação ao longo dos anos de 2011 e 2012, com a questão do investimento de 10\% do PIB em educação. É nesse novo quadro que passamos a analisar as características de 5 sindicatos de professores distribuídos pela cidade de Dourados, no Mato Grosso do Sul e pela Região Metropolitana de Curitiba, no Paraná.

\section{Diversidade de organização e prática sindical}

A organização sindical nos Estados do Mato Grosso do Sul e do Paraná refletem a história de heterogeneidade de organização dos trabalhadores em educação no Brasil. Apresentam-se aqui 5 casos que podem ilustrar essa diversidade das entidades: SIMTED - Sindicato Municipal dos Trabalhadores em Educação de Dourados (MS); ASMEF - Associação dos Trabalhadores em Educação Pública da Fazenda Rio Grande (PR); APMP Associação dos Professores Municipais de Piraquara (PR), SISMMAR - Sindicato dos Servidores do Magistério Municipal de Araucária (PR); SISMMAC - Sindicato dos Servidores do Magistério Municipal de Curitiba (PR).

Inicialmente cabe observar alguns elementos organizados no quadro 1 que caracterizam o surgimento de tais entidades. Observa-se que a fundação das entidades sindicais são posteriores a 1988; entretanto, apenas as duas Associações são efetivamente criadas na década de 2000 . Os três sindicatos têm uma história mais longa, que acompanha o histórico de transformação de entidades asso- 
ciativas em sindicais a partir da permissão na Constituição de 1988 da filiação sindical de servidores públicos. O SIMTED-Dourados é derivado da Associação Douradense de Professores (ADP), criada em maio de 1978; o SISMMAC é derivado da Associação do Magistério Municipal de Curitiba (AMMC), criada em 1973 - nesse caso houve uma associação anterior (Associação dos Professores Municipais de Curitiba) que teve vida entre 1971 e 1973 -; e o SISMMAR é derivado de uma Associação criada em 1986. Mas é importante registrar que mesmo as três associações fundadas anteriormente à Constituição de 1988, e que deram origem ao SIMTED-Dourados, ao SISMMAC e ao SISMMAR, não são tão antigas como as associações que originaram os Sindicatos de Docentes Estaduais. Nesse segundo caso, as associações são, em sua maioria, das décadas de 1940 e $1950^{6}$. Ao contrário, as três entidades municipais aqui analisadas são posteriores à reforma educacional que foi impulsionada pela Lei 5692/1971. Isso pode ter relação com o espírito descentralizador daquela legislação.

\begin{tabular}{|l|l|l|l|l|l|}
\hline Entidade & Fundação & $\begin{array}{l}\text { Filiados } \\
\text { (ano) }\end{array}$ & Como filia & $\begin{array}{l}\text { Filiação à } \\
\text { entidade estadual }\end{array}$ & $\begin{array}{l}\text { Filiação à } \\
\text { nacional }\end{array}$ \\
\hline SIMTED & 1989 & $1.787(2012)$ & $\begin{array}{l}\text { Por rede e por padrão de } \\
\text { 20 horas }\end{array}$ & FETMES & - \\
\hline ASMEF & 2002 & $305(2011)$ & Por padrões & APP-sindicato & - \\
\hline APMP & 2002 & $380(2011)$ & Por padrões de 20 horas & APP-sindicato & - \\
\hline SISMMAC & 1988 & $5.030(2010)$ & Por padrão de 20 horas & - & CNTE \\
\hline SISMMAR & 1989 & $1.100(2012)$ & Por padrão de 20 horas & -- & CNTE \\
\hline
\end{tabular}

QUADRO 1 - ORGANIZAÇÃO DE PROFESSORES, MUNICÍPIOS, PR E MS

FONTE: Entrevistas com dirigentes sindicais (dados organizados pelos autores).

A organização das duas associações de professores em Piraquara e na Fazenda Rio Grande são posteriores. Essas são cidades da Região Metropolitana de Curitiba, marcadas por forte expansão populacional após a década de 1990, o que implica expansão das redes de ensino e da contratação de pessoal. Especificamente sobre a criação da ASMEF, o percurso é muito peculiar, pois os professores iniciam o processo de construção de um sindicato municipal próprio. Entretanto, na sequência, avaliaram que a articulação de uma associação com apoio da APP-Sindicato ${ }^{7}$ seria mais interessante para o fortalecimento da enti-

${ }^{6}$ Vide o artigo de Gindin, neste mesmo dossiê.

${ }^{7}$ A APP-Sindicato é o Sindicato dos Trabalhadores em Educação Pública do Paraná. A base de representação da APP-Sindicato são todos os trabalhadores em educação da Rede Estadual de Ensino do Paraná e trabalhadores em educação de Redes Municipais de Ensino do Paraná, onde não existe um Sindicato Municipal representativo. Nesse caso, a APP-Sindicato atua em articulação com Associações Municipais. É o caso de Piraquara e Fazenda Rio Grande. 
dade. Assim, houve nesse caso uma assembleia de professores para transformar o sindicato em associação. Foi um movimento político peculiar e contraditório com a maioria dos casos nacionais, em que as assembleias de professores seguiram a tendência de transformar associações em sindicatos. Um dirigente da ASMEF explica o episódio:

\begin{abstract}
A ASMEF surgiu em 2002. Na verdade, em 2001 surgiu o SISMEF. Foi uma vontade coletiva dos professores. Na época a gente teve apoio de dois vereadores do Partido dos Trabalhadores do município, que eram o Lésli e a Lirani. Eles nos ajudaram a criar o SISMEF. A gente tinha poucas escolas, poucos professores. A gente sofria muito com a administração na época. E a gente resolveu lutar, se organizando. [...] Daí, trabalhamos um ano com o SISMEF. Aí, surgiu a oportunidade de se filiar à APP. Primeiro a gente chamou a APP, para se filiar à APP. Aí, descobrimos que nós não poderíamos nos filiar à APP porque nós já éramos um sindicato. Sindicato não se filia a sindicato. Foi, então, que a gente fez uma assembleia em 2002 e transformamos [sic] em ASSMEF, uma associação, em que a gente poderia então se filiar à APP (DIRIGENTE DA ASMEF, 2012).
\end{abstract}

Essa opção pode ser explicada pelas dificuldades em sustentar a ação sindical frente ao governo municipal. Nesse caso o peso da entidade estadual que tem uma trajetória política consolidada pode funcionar como um elemento de legitimação da ação da entidade nascente, mas também a articulação com a entidade estadual garante um patamar de infraestrutura para as associações especialmente no tocante à assessoria jurídica. Outro elemento importante, nesta análise, é o maior grau de impessoalidade, dado pela entidade estadual. Essa impessoalidade pode ser decisiva para quebrar o patrimonialismo e o personalismo das relações políticas locais. Ainda que essa explicação certamente não esgote a temática, outro aspecto interessa nessa questão, a trajetória não linear da organização de professores no Brasil. Ainda que em geral possamos reconhecer o caminho das associações que se transformam em sindicatos, o caso da ASMEF indica outra possibilidade que tem relação direta com a conjuntura política local.

Essa heterogeneidade de percursos se relaciona também com a heterogeneidade de interesses que se articulam nas entidades do magistério. Assim, ainda que sob a designação mais genérica de magistério ou trabalhadores em educação, os interesses corporativos em construção têm peculiaridades. Observem-se os aspectos do quadro 2 : 


\begin{tabular}{|l|l|l|}
\hline Entidade & Composição da base & Distribuição da base por Rede de Ensino \\
\hline SIMTED & $\begin{array}{l}\text { Todo trabalhador que exerça } \\
\text { atividades profissionais na Rede } \\
\text { Pública de Educação, Estadual e } \\
\text { Municipal, no respectivo Município. } \\
\text { Inclui aposentados. }\end{array}$ & $\begin{array}{l}\text { Rede municipal: Oferta educação infantil, } \\
\text { ensino fundamental - anos iniciais e } \\
\text { finais e modalidades. / Rede estadual: } \\
\text { Oferta de ensino fundamental - anos } \\
\text { inicias e finais do ensino fundamental, } \\
\text { ensino médio e modalidades. }\end{array}$ \\
\hline ASMEF & $\begin{array}{l}\text { Professores e trabalhadores da } \\
\text { educação nas escolas e Centros de } \\
\text { Educação Infantil. }\end{array}$ & $\begin{array}{l}\text { Rede municipal: Oferta educação infantil, } \\
\text { ensino fundamental - anos iniciais e } \\
\text { modalidades. }\end{array}$ \\
\hline APMP & $\begin{array}{l}\text { Professores e trabalhadores da } \\
\text { educação nas escolas e Centros de } \\
\text { Educação Infantil. }\end{array}$ & $\begin{array}{l}\text { Rede municipal: Oferta educação infantil, } \\
\text { ensino fundamental - anos iniciais e } \\
\text { modalidades. }\end{array}$ \\
\hline SISMMAC & $\begin{array}{l}\text { Professores e pedagogos. Inclui } \\
\text { aposentados. Não representa demais } \\
\text { trabalhadores em educação. }\end{array}$ & $\begin{array}{l}\text { Rede municipal: Oferta educação infantil, } \\
\text { ensino fundamental - anos iniciais e } \\
\text { finais e modalidades. }\end{array}$ \\
\hline SISMMAR & $\begin{array}{l}\text { Professores e pedagogos. Inclui } \\
\text { aposentados. Não representa demais } \\
\text { trabalhadores em educação. }\end{array}$ & $\begin{array}{l}\text { Rede municipal: Oferta educação infantil, } \\
\text { ensino fundamental - anos iniciais e } \\
\text { finais e modalidades. }\end{array}$ \\
\hline
\end{tabular}

QUADRO 2 - COMPOSIÇÃO DA BASE DAS ENTIDADES DE PROFESSORES, MUNICÍPIOS, PR E MS

FONTE: Entrevistas com dirigentes sindicais (dados organizados pelos autores).

As tensões entre os diferentes interesses sintetizados em cada rede de ensino foram indicados de diversas formas pelos dirigentes sindicais entrevistados e decorrem, em grande medida, da lógica instituída no sistema escolar brasileiro, onde o trabalho docente tem certa diferenciação por área de atuação, que se relaciona com uma histórica desvalorização do trabalho com crianças pequenas, por um lado, e por outro, pela diversificação dos trabalhadores que atuam nas diferentes etapas. A diferenciação no interior do magistério de ensino fundamental é expressa, por exemplo, na avaliação de uma diferença entre o nível de envolvimento dos professores das séries iniciais e das séries finais com a ação sindical:

Eu como sou de $1^{\mathrm{a}}$ a $4^{\mathrm{a}}$ posso falar. Às vezes, eu acho que tem um pouco de conteúdo de preconceito. Em alguns locais dizem que quem toma conta da luta é de $5^{\mathrm{a}}$ a $8^{\mathrm{a}}$. Só que assim, em muitos momentos, a gente repetiu esse discurso de quem está à frente é o professor de $5^{\mathrm{a}} \mathrm{a}$ $8^{\mathrm{a}}$, naquele aspecto cultural de que é o cara formado. Grande parte são homens. Mas, eu vejo que isso tem mudado. Eu acho que os professores de $1^{\mathrm{a}}$ a $4^{\mathrm{a}}$ têm opinado, tanto, que nos conselhos de base, grande parte é de $1^{\mathrm{a}}$ a $4^{\mathrm{a}}$. Mas assim, grande parte das interferências nas assembleias 
são professores de $5^{\mathrm{a}}$ a $8^{\mathrm{a}}$. É porque de $5^{\mathrm{a}}$ a $8^{\mathrm{a}}$ nós percebemos que têm pessoas com militância em outros movimentos e tal. E a característica de $1^{\mathrm{a}}$ a $4^{\mathrm{a}}$ a gente percebe que são a maioria mulheres. Algumas foram para a universidade já tardiamente. Entraram com nível médio. Então, toda esta estratégia tem que ser levada em consideração (DIRIGENTE DO SISMMAR, 2012).

No caso das diferenças entre o ensino fundamental e a educação infantil, a tensão é maior, pois a incorporação das creches ao sistema educacional é dos anos de 1990, em função da LDB de 1996, e a expansão dessa etapa da educação básica em muitos municípios implicou diversificação de profissionais. Além dos professores, é comum, na etapa de educação infantil, que os trabalhadores da educação tenham cargos denominados educadores infantis (Curitiba), educador de infância (Fazenda Rio Grande). Nesse caso, há diferenças substanciais na carreira, na jornada de trabalho e nas condições de remuneração que podem significar conflitos na construção da luta por melhores condições de trabalho. Também há diferenças na representação sindical. Sindicatos como o SISMMAC e o SISMMAR, no qual apenas se representam professores e pedagogos, os educadores se encontram filiados aos sindicatos de servidores públicos. Isso não ocorre da mesma forma no SIMTED-Dourados, na ASMEF e na APMP, que filiam todos os trabalhadores em educação. Um dos dirigentes entrevistados destaca essas tensões:

Com a implantação do novo plano de carreira todos eles tiveram equiparação salarial junto ao professor. Por exemplo, se o professor ganhou $\mathrm{R} \$ 25,00$, o educador de infância ganhou $\mathrm{R} \$ 300,00$. Todos os educadores passaram de $\mathrm{R} \$ 1.005,00$ para $\mathrm{R} \$ 1.450,00$. Então eles vão ter uma melhoria de $\mathrm{R} \$ 450,00$ no salário, e agora dia 30 de julho eles vão receber esse retroativo de janeiro, que dá $R \$ 450,00$ vezes 6 . Teve um impacto, um avanço pra eles. Vocês [refere-se a outro dirigente] sofreram bastante na hora de falar isso para os professores, que eles teriam $\mathrm{R} \$$ 25 e os educadores R \$ 450. Então houve uma ruptura. Na verdade, a gente fez uma assembleia no final do ano passado, bem no último dia de aula. Na assembleia ia ser aprovado isso, e teve algumas na assembleia que discordaram, mas era minoria. As que realmente eram contra não apareceram. Então é democrático. [...] Os próprios professores eram contra a equiparação, não porque eles não queriam que os educadores ganhassem o piso, mas porque eles também queriam um valor parecido no aumento de salário (Entrevista 2, 2012). 
Essa diversificação da base causa discussões quando todos são representados pelo mesmo sindicato, mas também é ponto de conflito entre os sindicatos da educação e sindicatos de servidores em geral, quando professores e demais trabalhadores de educação se encontram em diferentes sindicatos. Em outro caso municipal, onde há essa separação da representação sindical, a situação é ilustrada na seguinte forma:

Desde $2008^{8}$ que a educação infantil passou a vincular na educação. E daí, teve a exigência de magistério e agora tem gente até de ensino superior, formado em pedagogia, que vem lutando para incorporar no quadro próprio do magistério. Eles tinham feito um caminho contrário. Eles queriam vir para o SISMMAR primeiro, para, daí, ele encampar essa luta. Aí, eles estão hoje no sindicato dos demais funcionários. Essa luta "tá" bem latente nesse momento. Há uma comissão formada para discutir a nomenclatura do cargo (DIRIGENTE DO SISMMAR, 2012).

Essa composição de instituições nas diferentes etapas da educação básica nas redes de ensino implica um número grande de locais de trabalho para os profissionais, o que demanda uma organização específica dos sindicatos/associações para organizar o cotidiano da ação sindical. A estrutura existente, nos cinco casos em questão, incorpora dirigentes liberados e representação por local de trabalho. Observa-se uma variedade de tamanhos nas direções sindicais que tem relação direta com o tamanho da base sindical e da estrutura consolidada para a representação. Mas alguns elementos de relação com os poderes locais facilitam ou dificultam conjunturalmente a organização - caso, por exemplo, da ASMEF, em que, apesar do número de filiados à Associação possibilitar a liberação de um dirigente sindical de suas atividades na escola para a ação sindical e esta possibilidade estar definida no plano de carreira, durante o ano de 2012, tal regra não estava sendo cumprida.

O formato de jornada de trabalho dos professores no Brasil tem uma diferenciação grande. No caso do Paraná e do Mato Grosso do Sul, a jornada mais comum é de 20 horas semanais, o que, em geral, significa um turno de trabalho. Na educação infantil é bastante comum que os cargos de educador sejam de 40 horas semanais, o que significam dois turnos de trabalho. Essa jor-

${ }^{8}$ Apesar da LDB, em 1996, ter incorporado a educação infantil à educação básica, o conflito de interesses entre profissionais do ensino fundamental e da educação infantil ganha nova dimensão política, para o Sindicato de Araucária, no momento do debate sobre o Plano de Carreira, em 2008. 
nada é coincidente com a jornada de trabalho de outros profissionais na escola (secretários, assistentes de serviços gerais). Essa diversificação das jornadas explica a diferenciação entre liberação de pessoas (independente da jornada) ou de carga horária (independente do número de pessoas) que pode ser flagrada no quadro 3. No entanto, chama atenção a diferenciação na representação por local de trabalho, visto que neste ponto não há nenhum peso legal do formato de organização do trabalho na escola. A diferenciação entre o SIMTED-Dourados e os demais sindicatos/associações (o primeiro tem um representante por turno em cada local de trabalho, enquanto os demais apenas um representante por local de trabalho) se deve exclusivamente a opções políticas, dentro da conjuntura local.

\begin{tabular}{|l|l|l|l|l|}
\hline Entidade & Diretoria & Liberados & $\begin{array}{l}\text { Representação } \\
\text { por local de } \\
\text { trabalho }\end{array}$ & $\begin{array}{l}\text { Organização dos } \\
\text { representantes por } \\
\text { local de trabalho }\end{array}$ \\
\hline SIMTED & 20 componentes & $\begin{array}{l}3 \text { pessoas da } \\
\text { rede estadual } \\
6 \text { pessoas com } \\
20 \text { horas cada }\end{array}$ & $\begin{array}{l}\text { Representante } \\
\text { por turno de } \\
\text { funcionamento da } \\
\text { escola }\end{array}$ & $\begin{array}{l}\text { Conselho de } \\
\text { representantes sem } \\
\text { previsão de data }\end{array}$ \\
\hline ASMEF & 6 componentes & $\begin{array}{l}\text { Não tem nenhum } \\
\text { liberado }\end{array}$ & $\begin{array}{l}\text { Um representante } \\
\text { por escola/ } \\
\text { instituição }\end{array}$ & $\begin{array}{l}\text { Conselho de } \\
\text { representantes sem } \\
\text { previsão de data }\end{array}$ \\
\hline APMP & 6 componentes & $\begin{array}{l}60 \text { horas de } \\
\text { liberação }\end{array}$ & $\begin{array}{l}\text { Um representante } \\
\text { por escola/ } \\
\text { instituição }\end{array}$ & $\begin{array}{l}\text { Conselho de } \\
\text { representantes mensal }\end{array}$ \\
\hline SISMMAC & 28 componentes & 7 pessoas & $\begin{array}{l}\text { Um representante } \\
\text { por escola/ } \\
\text { instituição }\end{array}$ & $\begin{array}{l}\text { Conselho de } \\
\text { representantes mensal }\end{array}$ \\
\hline SISMMAR & 15 componentes & 3 pessoas & $\begin{array}{l}\text { Um representante } \\
\text { por escola/ } \\
\text { instituição }\end{array}$ & $\begin{array}{l}\text { Conselho de } \\
\text { representantes mensal }\end{array}$ \\
\hline
\end{tabular}

QUADRO 3 - COMPOSIÇÃO DA DIREÇÃO DAS ENTIDADES DE PROFESSORES, MUNICÍPIOS, PR E MS

FONTE: Entrevistas com dirigentes sindicais. Páginas das entidades na rede mundial de computadores (dados organizados pelos autores).

Essa organização dos sindicatos pressupõe o acompanhamento das questões trabalhistas, mas também de maneira crescente o acompanhamento da política educacional. Assim, encontramos um número expressivo de conselhos e comissões que as entidades integram. O quadro 4 apresenta um panorama daquelas instâncias que os dirigentes sindicais entrevistados identificaram como áreas de atuação das direções ou conselhos em que a categoria tem representantes indicados via assembleias. Este quadro não pretende ser exaustivo dos espaços institucionais, porém consegue mapear instâncias que são de negociação mais 
estritamente corporativa (por exemplo, Comissão de Avaliação de Desempenho) e espaços de disputa da política educacional (por exemplo, Conselho Municipal de Educação).

\begin{tabular}{|l|c|c|c|c|c|}
\hline Conselho & SIMTED & ASMEF & APMP & SISMMAC & SISMMAR \\
\hline $\begin{array}{l}\text { Conselho Municipal de } \\
\text { Educação }\end{array}$ & $\mathrm{X}$ & $\mathrm{X}$ & $\mathrm{X}$ & $\mathrm{X}$ & $\mathrm{X}$ \\
\hline $\begin{array}{l}\text { Conselho de } \\
\text { Acompanhamento e } \\
\text { Controle Social do } \\
\text { FUNDEF/FUNDEB }\end{array}$ & $\mathrm{X}$ & $\mathrm{X}$ & $\mathrm{X}$ & $\mathrm{X}$ & $\mathrm{X}$ \\
\hline $\begin{array}{l}\text { Conselho da Alimentação } \\
\text { Escolar }\end{array}$ & $\mathrm{X}$ & & $\mathrm{X}$ & $\mathrm{X}$ & $\mathrm{X}$ \\
\hline Comissões específicas & & & $\begin{array}{l}\text { Avaliação de } \\
\text { desempenho / } \\
\text { Revisão do Plano } \\
\text { de Carreira }\end{array}$ & & \\
\hline
\end{tabular}

QUADRO 4 - REPRESENTAÇÃO EM CONSELHOS, MUNICÍPIOS, PR E MS

FONTE: Entrevistas com dirigentes sindicais. Páginas das entidades na rede mundial de computadores (dados organizados pelos autores).

O quadro 4 evidencia uma participação mais acentuada em Conselhos amplos que debatem pautas gerais da educação. Somente no caso da APMP aparece uma comissão para tratar de questões tipicamente corporativas. Esse quadro, de certa maneira se torna paradoxal. O sindicalismo, via de regra, é descrito como atividade corporativa. Em nosso próprio texto, descrevemos a convivência entre as entidades sindicais docentes, de corte corporativo, e as entidades associativas mais amplas sobre a temática educacional. Como, portanto, explicar esta ênfase da participação sindical em conselhos que lidam diretamente com a política educacional, em detrimento das questões corporativas? Este texto não é capaz de elucidar a questão, mas podemos arriscar hipóteses para orientar trabalhos futuros. A ausência de conselhos e comissões para debater as questões corporativa e trabalhista dos professores não deve ter vinculação com a postura dos sindicatos, mas com o autoritarismo e o patrimonialismo intrínseco do sistema político brasileiro, principalmente em seu nível municipal. Da mesma maneira, o corporativismo suposto da ação sindical não pode ser negado pela simples constatação de sua atuação em Conselhos amplos de formulação e fiscalização da política educacional, mas somente através da análise do conteúdo da pauta defendida pelos representantes sindicais nesses espaços. Nos dois casos, falta material empírico a este texto para traçar um diagnóstico preciso. 


\section{À guisa de conclusão}

Ao partir de pressupostos retirados de uma análise histórica do movimento sindical docente - coexistência entre ações corporativas e disputa pelos rumos da política educacional, coexistência entre entidades de representação de interesses corporativos e generalistas, e diversidade de representação em função da descentralização dos Sistemas de Ensino no Brasil -, este texto procurou flagrar os desafios locais que foram enfrentados por sindicatos e associações de professores, em cinco municípios dos estados do Mato Grosso do Sul e do Paraná, e a solução que dirigentes e demais trabalhadores da educação encontraram ao longo de suas lutas por reconhecimento e valorização profissional.

Apenas reconhecer a heterogeneidade das situações seria muito tímido para um texto que procura, a partir de dados empíricos inéditos, diagnosticar singularidades locais, assim como traçar reflexões abstratas que de forma indutiva possam sinalizar para generalizações teóricas. Assim, parece-nos que entre a capacidade organizativa dos professores e o desenvolvimento da política educacional existem vínculos dialéticos profundos. A força mobilizatória dos professores é influenciada pela existência regular e expansiva das redes de ensino, da mesma forma que as redes de ensino, muitas vezes, se ampliam e se diversificam em função da força corporativa dos professores. No quadro 1, que compara os anos de fundação dos sindicatos/associações, essa questão se torna explícita.

No entanto, esse vínculo pode ser causa/consequência, tanto do fortalecimento e unificação da ação sindical quanto de sua fragmentação. É neste ponto que o quadro 2 é revelador para se compreender como a separação das Redes de Ensino por entes federados consolida interesses divergentes no interior do movimento sindical docente. Da mesma maneira - e ainda perseguindo os dados revelados no quadro 2 - a consolidação de uma estrutura sindical concreta - neste caso, a representação apenas de professores e pedagogos no SISMMAC e no SISMMAR - pode transformar qualitativamente o debate - neste caso a incorporação dos profissionais da educação infantil no quadro geral do magistério.

O quadro 3 também vai reforçar - ao verificar a conexão entre as regras de liberação sindical e organização do trabalho escolar por turno - aquela já explícita vinculação da política educacional com a organização sindical. Mas é no quadro 4 que fomos obrigados a pensar além do que os próprios pressupostos teóricos nos indicavam. Pois até esse quadro, o raciocínio se limitava a evidenciar influências mútuas já presumidas. No entanto, o quadro 4 sugere que tais relações não são apenas de uma dialética simples. A influencia $\mathrm{B}$, que por 
seu turno influencia A, no sentido de que A e B são dois polos diferenciados. Ao contrário, o verificado empiricamente nos possibilita pensar em uma ação sindical corporativa A, que é intrinsecamente política educacional B. Mas esse é um outro debate para uma outra ocasião.

\section{REFERÊNCIAS}

ALMEIDA, M. H. T. O corporativismo em declínio? In: DAGNINO, E. (Org.) Os anos 90: política e sociedade no Brasil. São Paulo: Brasiliense, 1996.

ARENDT, H. Origens do totalitarismo. São Paulo: Companhia das Letras, 1989.

BIASOTTO, W; TETILA, L. O movimento reivindicatório do Magistério Público Estadual de Mato Grosso do Sul - 1978-1988. Campo Grande: UFMS, 1991.

BOBBIO, N. Dicionário de política. Brasília: Editora UnB, 2004.

BOITO JR, A. De volta para o novo corporativismo: a trajetória política do sindicalismo brasileiro. São Paulo em Perspectiva, São Paulo, n. 3, Fundação Seade, 1994.

BULHÕES, M. G; ABREU, M. A luta dos professores gaúchos - 1979/1991: o difícil aprendizado da democracia. Porto Alegre: L\&PM, 1992.

CAMARGO, R. B; JIACOMINI, M. A. Carreira e salário do pessoal docente da educação básica: algumas demarcações legais. Educação em Foco, Belo Horizonte, n. 17, p. 129-167, jul. 2011.

CARDOSO, A. M. A década neoliberal e a crise dos sindicatos no Brasil. São Paulo: Boitempo, 2003.

DIRIGENTE DO SIMTED - SINDICATO DOS TRABALHADORES DE EDUCAÇÃO DE DOURADOS Entrevista concedida a Marcos Ferraz. Dourados, 2011.

DIRIGENTE DAASMEF - ASSOCIAÇÃO DOS TRABALHADORES MUNICIPAIS EM EDUCAÇÃO PÚBLICA DE FAZENDA RIO GRANDE. Entrevista concedida a Andrea Gouveia, Debora Donato e Sandra Pereira. Fazenda Rio Grande, 2012.

DIRIGENTE DA APMP - ASSOCIAÇÃO MUNICIPAL DE PROFESSORES DE PIRAQUARA. Entrevista concedida a Andrea Gouveia, Debora Donato e Sandra Pereira. Piraquara, 2012.

DIRIGENTE DO SISMMAR - SINDICATO DO MAGISTÉRIO MUNICIPAL DE ARAUCÁRIA Entrevista concedida a Andrea Gouveia, Debora Donato e Sandra Pereira. Araucária, 2012. 
DIRIGENTE DO SISMMAC - SINDICATO DO MAGISTÉRIO MUNICIPAL DE CURITIBA. Entrevista concedida a Debora Donato. Curitiba, 2011.

FERREIRA JÚNIOR, A. Professores e Sindicalismo em Mato Grosso do Sul: 1979-1986. Campo Grande: UFMS, 2003.

GEROLOMO, A. C. Trabalhadores do Ensino e APEOESP: uma relação de conflito (1978-1987). São Paulo: Annablume, 2009.

LEFORT, C. A invenção democrática: os limites do totalitarismo. São Paulo: Brasiliense, 1987.

NOGUEIRA, A. J. F. M. A liberdade desfigurada. São Paulo: Expressão Popular, 2005.

RANCIÈRE, J. O desentendimento: política e filosofia. São Paulo: Ed. 34, 1996.

REIS, B. P. W. Corporativismo, pluralismo e conflito distributivo no Brasil. Dados, Rio de Janeiro, v. 38, n. 3, p. 417-457, 1995.

ROMANELli, O. O. História da educação no Brasil. Petrópolis: Vozes, 1996.

SUBIRÁ, J. A. A. Um panorama da remuneração inicial dos professores nos municípios do primeiro anel metropolitano de Curitiba: configurações, impasses e perspectivas. Dissertação (Mestrado em Educação - PPGE/UFPR, Curitiba, 2012.

TELLES, V. S. Direitos sociais: afinal do que se trata? Belo Horizonte: UFMG, 1999.

VICENTINI, P. P; LUGLI, R. História da profissão docente no Brasil. São Paulo: Cortês, 2009.

Texto recebido em 10 de outubro de 2012.

Texto aprovado em 25 de outubro de 2012. 